\title{
Manual Aseptic Liquid Filling Method
}

National Cancer Institute

\section{Source}

National Cancer Institute. Manual Aseptic Liquid Filling Method. NCI Thesaurus. Code

C112989.

A process that fills a dosage unit with a liquid, which is performed under sterile conditions and is likely to involve human intervention. 